\title{
NON-UNIFORMITY OF THE COMBUSTOR EXIT FLOW TEMPERATURE IN FRONT OF THE GAS TURBINE
}

\author{
Józef BŁACHNIO*, Wojciech I. PAWLAK \\ *Bialystok University of Technology, Faculty of Mechanical Engineering, ul. Wiejska 45C, 15-351, Białystok, Poland \\ *Air Force Institute of Technology, ul. Księcia Bolesława 6, 01-494 Warszawa, Poland \\ j.blachnio@pb.edu.pl,wojciech.pawlak@itwl.pl
}

\begin{abstract}
Various types of damages to gas-turbine components, in particular to turbine blades, may occur in the course of gas turbine operation. The paper has been intended to discuss different forms of damages to the blades due to non-uniformity of the exit flow temperature. It has been shown that the overheating of blade material and thermal fatigue are the most common reasons for these damages. The paper presents results from numerical experiments with use of the computer model of the aero jet engine designed for simulations. The model has been purposefully modified to take account of the assumed non-homogeneity of the temperature field within the working agent at the turbine intake. It turned out that such non-homogeneity substantially affects dynamic and static properties of the engine considered as an object of control since it leads to a lag of the acceleration time and to increase in fuel consumption. The summarized simulation results demonstrate that the foregoing properties of a jet engine are subject to considerable deterioration in pace with gradual increase of the assumed non-homogeneity of the temperature field. The simulations made it possible to find out that variations of the temperature field nonhomogeneity within the working agent at the turbine intake lead to huge fluctuation of the turbine rpm for the idle run.
\end{abstract}

Key words: Gas Turbine, Blade, Simulation Model, Working Agent Temperature Field, Health/Maintenance Status

\section{INTRODUCTION}

A turbine is a component included in the thermal turbomachinery category. It converts enthalpy of the working medium, also called the working fluid (exhaust stream, gaseous decomposition products or compressed gas), into the mechanical work, which results in the rotation of the rotor. The advantages of gas turbines such as the ability to develop high power in a compact and lowweight structure, relatively high energy conversion efficiency of the process, simple structure, ease of use under different climatic conditions (particularly, at low ambient temperatures), and a fairly high reliability have made it were widely used in, e.g. power engineering, traction, marine and aircraft engines, and aerospace technology. Unfortunately, gas turbines have also their drawbacks, the most essential being high operating temperature of some of their parts such as blades, and large rotor speeds.
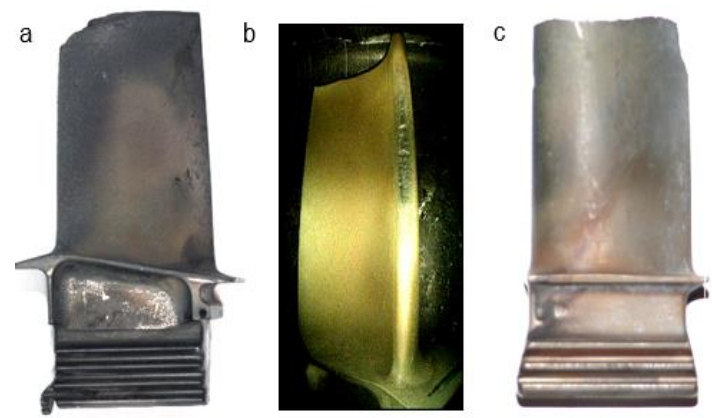

Fig. 1. Instances of thermal damages to gas turbine blades:

a) - the region of material overheating at the end of the leading edge, b) - overheating region and a fracture on the leading edge, c) - the blade broken off due to material overheating (Spychała et al., 2008)
Different types of damages to gas turbine components keep occurring throughout the whole process of their exploitation (Błachnio and Pawlak, 2011; Błachnio et al., 2014; Bogdan and Błachnio, 2010). Parts of the turbine that are most vulnerable to damages are blades, the condition of which is crucial to the reliability and service life of the entire turbine and a system it is built (Marsh, 2013). The main reasons why gas turbine blades get damaged are the overheating and thermal fatigue (Fig. 1).

The reaction of blade material to mechanical loads depends mainly on its operating temperature. To select material to produce a blade of some specific strength one should take account of mechanical properties and stresses in the region of the maximum blade temperature (Błachnio and Pawlak, 2011). A typical temperature distribution along the blade is severely non-uniform (Fig. 2).

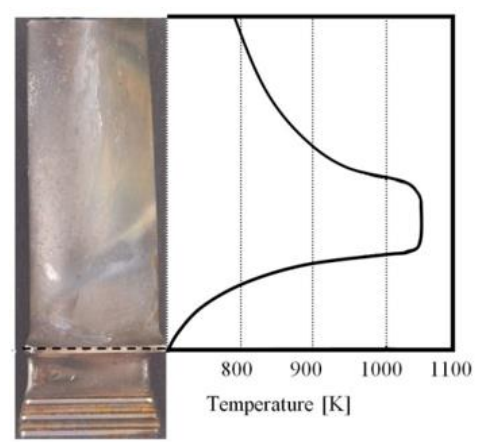

Fig. 2. Typical temperature distribution along the gas turbine blade (Bogdan and Błachnio, 2010)

The blade overheating results from the permissible average values of the exit-flow temperature being exceeded. Another reason is a non-uniform temperature distribution along the turbine 
blade-rim circumference (Fig. 3). The non-uniform temperature distribution behind the turbine results, in turn, from fuel being incorrectly sprayed by fuel injectors in the combustion chamber. Most often, the problem is effected by carbon deposits from fuel of poor quality/properties (Żółtowski and Cempel, 2004; Spychała et al., 2008).

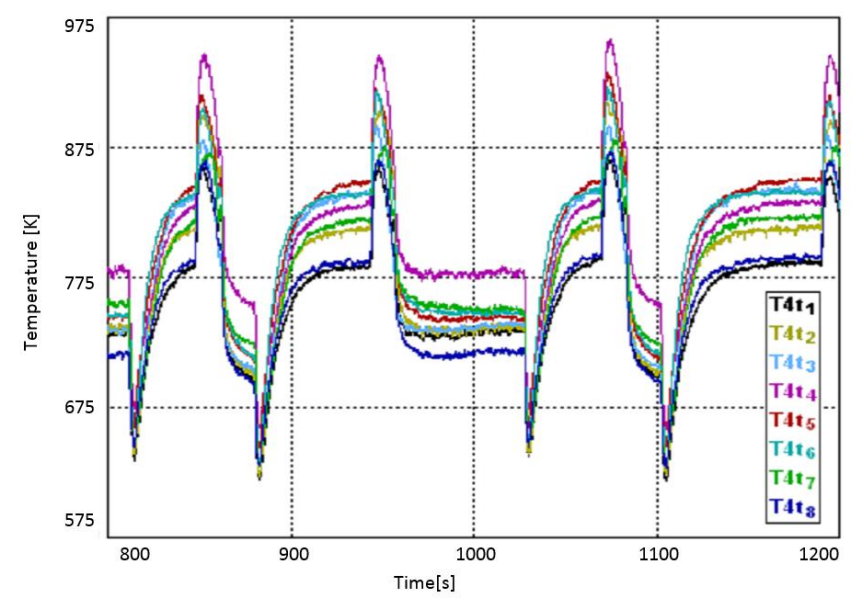

Fig. 3. Instantaneous circumferential non-uniform temperature $T_{4}$ distribution measured with eight thermocouples $\left(\mathrm{T}_{4} \mathrm{t}_{1}-\mathrm{T} 4 \mathrm{t}_{8}\right)$ located behind the turbine; measurements taken at increasing/ decreasing rotational speeds (Błachnio and Pawlak, 2011)

A damage to at least one blade among dozens around the blade rim may result in a gas-turbine failure, or even destruction. Therefore, the question of uniform temperature distribution along the blade, and in particular, along the circumference of the gas-turbine blade rim proves extremely significant as referred to gas turbine power and reliability (Swadźba et al., 2008).

\section{SPECIFIC PROPERTIES OF A TURBINE ENGINE AS A NON-LINEAR OBJECT}

All versions of the simulation model for the jet engine that have already been published by (Pawlak et al., 2003; Pawlak, 2010) comprise considerable number of non-linear parameters. In particular, these include static characteristics of the compressor and the turbine. The theory of control says that in case when at least one component in the computation structure is non-linear, the entire structure is non-linear as well (Pismenny and Levy, 2002). Thus, a turbine jet engine, considered as an object of control, is a dynamic nonlinear object. Such an important feature of a turbine engine, resulting from that fact that the engine is a non-linear dynamic object, is the impact of the temperature field non-homogeneity within the working agent at the outlet of the combustion chamber onto the acceleration time and performance at steady conditions.

Procedures of handover /takeover tests of engines at manufacturing plants as well as routine tests after overhauls include measurements of the temperature field (Dzida, 2000). In most cases, due to practical reasons, the temperature field non-homogeneity is measured within a cross-section of the jet nozzle duct with use of dedicated equipment. The reasons for non-homogeneity may be various and in practice the phenomenon is very difficult for total eradication (Dzida, 2000). The most common method that can be applied consists in appropriate calibration and selection of a matching set of working injectors. Fig. 4 shows an example graph that depicts non-homogeneity of temperature field across the jet nozzle of a prototype K-16 engine (slightly altered version of the K-15 engine). The image was acquired by means of the measuring testbench shown in Fig. 5. The testbench is made up of two sets of thermocouples, with 7 units in each set, deployed between the inner and outer walls of the jet duct within its cross-section. The measurements are taken by simultaneous readouts from all 14 thermocouples at a time for various angle positions of the entire arrangement selected by its revolution around the longitudinal axis.



Fig. 4. Example results for measurements of the temperature field non-homogeneity within the working agent inside the jet nozzle of the K-16 engine. $a$ - nearby the outer wall, $b-$ in the middle of the gas duct radius, $\mathrm{c}-$ nearby the inner wall

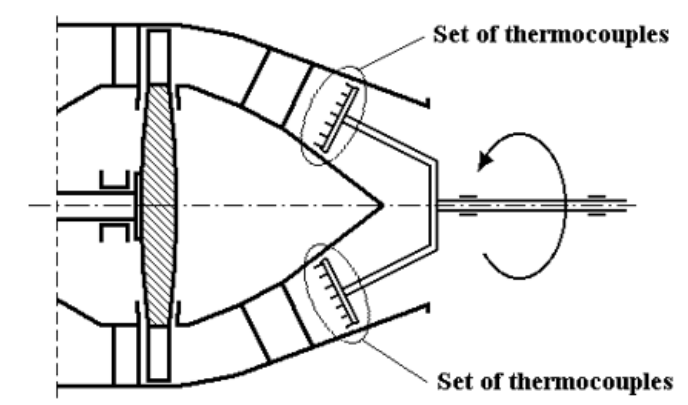

Fig. 5. Diagram of an appliance for measurement of the temperature field non-homogeneity within the working agent in the engine jet nozzle

The measurement results depicted in Fig. 4 indicate that nonhomogeneity of the temperature field for the cross-section of the working agent flux is surprisingly large and subject to some fluctuations in spite of the constant rpm of the rotor. The size of such fluctuations can be expressed as discrepancies of temperatures measured for the same measurement points but after elapsing of time necessary for displacements of the measurement arrangement by the angle of $180^{\circ}$ (see temperature differentials for 'azimuths" of $0^{\circ}$ and $180^{\circ}$ ).

The simulation model for the SO-3 engine (Pawlak et al., 2003; Pawlak, 2010) presented involves description of the working agent parameters within selected cross-sections of the gas duct with use of the 'zero-dimensional' approach. Thus, such a description is incapable of considering such nuances as 3D nature of the working agent flow, in particular through the so called 'hot part' of the engine. 


\section{PLAN FOR A NUMERICAL EXPERIMENT WITH USE OF A SIMULATION MODEL}

The idea of this paper consists in suggestion to modify the structure of the engine model with the aim to achieve a kind of a simple mathematical dummy that enables simulation of the temperature field non-homogeneity within the working agent at the combustion chamber outlet, where the simulation is carried out with use of basically zero-dimensional description of the working agent flow.



Fig. 6. The basic principal diagram of a turbojet engine:

W - engine intake, $\mathrm{S}$ - compressor, KS combustion chamber,

$T$ - turbine, $D$ - exhaust nozzle jet, $Q$ - fuel expenditure

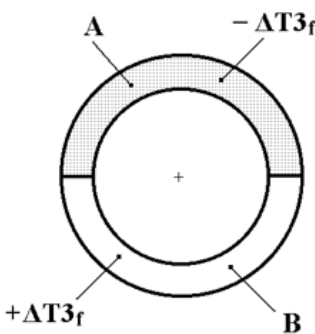

Fig. 7. Conventional breakdown of the cross-section area for the outlet duct of the combustion chamber (or the intake duct of the turbine)

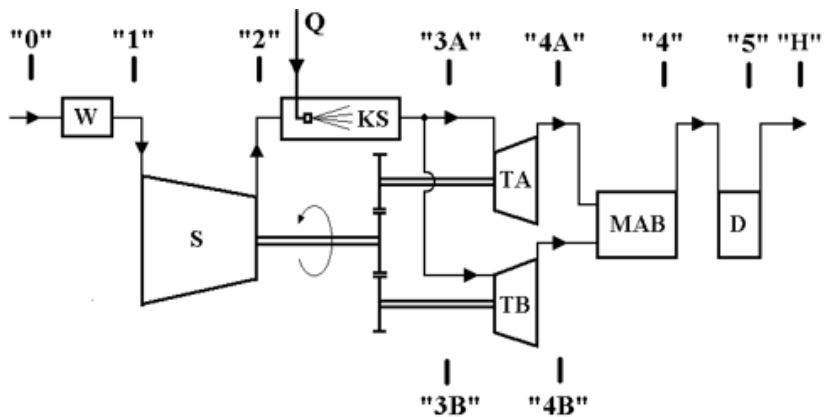

Fig. 8. The schematic diagram for the engine model - a mathematical dummy for simulation of the temperature field non-homogeneity within the working agent at the turbine intake: $\mathrm{W}$ - engine intake, $S$ - compressor, KS combustion chamber, TA - turbine (part ' $A$ '), $T B$ - turbine (part ' $B$ '), MAB mixing area, $D$ - nozzle jet, $Q$ - fuel expenditure

Fig. 6 depicts the general structure of the engine. This diagram was used as the outset point to develop the simulation model already described in (Pawlak et al., 1996; Pawlak and Balicki, 2003). Figs. 7 and 8 depict upgraded version of that model where both the turbine and the combustion chamber are split into mutually equal parts. Each of the TA and TB turbines has the same efficiency characteristic curve, whilst the flow characteristic curves are equiv- alent to a half of the working agent flux (Driankov et al., 1966; Stewart, 2001).

With regard to the split combustion chamber the assumption was made that a different temperature of the working agent should be measured at the outlet of each turbine half, which is the result of random and difficult to explain fluctuations of the temperature field. The conventional diagram split in that way into two mutually equal cross-section areas of the outlet duct of the combustion chamber is shown in Fig. 7.

\section{RESULTS FROM THE NUMERICAL EXPERIMENT CARRIED OUT WITH USE OF THE SIMULATION MODEL}

The upgraded model for the SO-3 engine as described above was then combined with the model for the automatic control circuit, not shown in the drawing (Pismenny and Levy, 2002). The control circuit enables execution of simulated control for transition processes and generation of selected steady states. Two types of numerical experiments were carried out. The first type assumed investigation into how the non-homogeneity of the temperature field affects transition processes within the engine. The second series of investigations was dedicated to check impact of the temperature field non-homogeneity onto static characteristics of the engine (Wróbel, 2004).

The transition processes were triggered by quick subsequent accelerations and decelerations, starting for the idle run of the engine up to nearly the maximum thrust with due care to avoid tripping the limiter for the maximum engine rpm. The experiments were carried out with the presumed values of the $\Delta \mathrm{T} 3_{\mathrm{f}}$ parameter that represents the measure of non-homogeneity of the temperature field distribution at the outlet of the combustion chamber (or at the turbine intake). Examples of obtained results are depicted in Fig. 9 to Fig. 11.

The selected static characteristic curves of the engine are shown in Fig. 9 to Fig. 11. These curves were plotted for the engine operation under normal atmospheric conditions on the ground ( $\mathrm{Ma}=0, \mathrm{H}=0$ ) and for flights at the speed of $\mathrm{Ma}=0.4$ under normal atmospheric conditions at the altitude of $6 \mathrm{~km}$. For that purpose the own-developed method proposed by the author was applied, referred to as scanning of the engine status space and described in details in Pawlak (2010). That method, verified in Pawlak and Balicki (2003) and Błachnio and Pawlak (2011) for determination of static characteristic curves for the K-15 engine, prevails over the conventional one, typically used for the same purpose because it enables collection of great many points with measurement results, which is shown in Fig. 9 to Fig. 11.

\subsection{Simulation of selected transition processes}

Results from simulation of transition processes for the case in which the engine runs under normal ground conditions are shown in Fig. 9 to Fig. 11. Excitation of the transition processes was carried out by input waveforms of fuel expenditures for three 3 values of the $\Delta \mathrm{T} 3_{\mathrm{f}}$ parameter as shown in Fig. 9.

The presented results feature with some distinctive properties:

- Values of all engine parameters presented in graphs plotted for steady states clearly depend on the value of the $\Delta T 3_{f}$ parameter in spite of the fact that the fuel expenditure observed for steady states and shown in Fig. 9 is exactly the same for all values of the $\Delta \mathrm{T} 3_{\mathrm{f}} \mathrm{f}$ parameter, 
- Duration of the acceleration and deceleration periods are substantially different for all monitored engine parameters ( $\mathrm{n}$, Thrust, $\mathrm{C}_{\mathrm{j}}$ ) and depend on the value of the $\Delta \mathrm{T} 3_{\mathrm{f}}$ parameter.

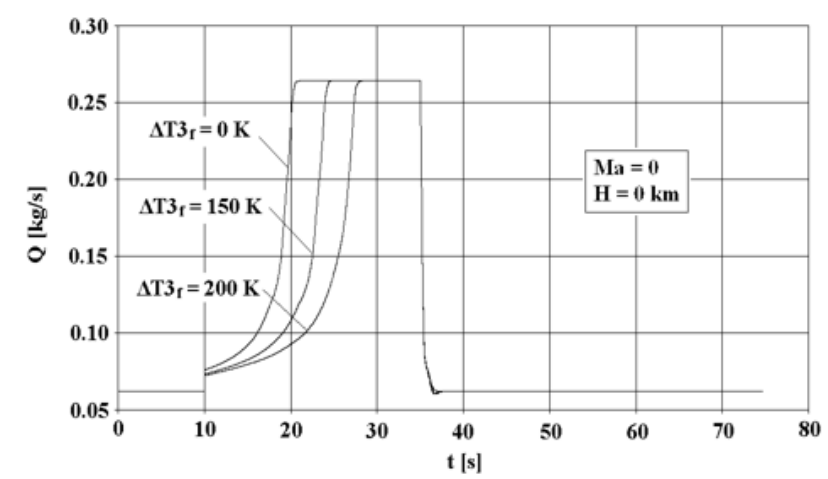

Fig. 9. Timings for fuel expenditures during acceleration and deceleration of the jet engine within the range from idle run to the area slightly below full thrust without tripping the limiter of the maximum rotor rpm, under normal ambient conditions on the ground and for various settings for the $\Delta \mathrm{T} 3_{\mathrm{f}}$ parameter



Fig. 10. Timings for the rotor rpm during acceleration and deceleration of the jet engine within the range from idle run to the area slightly below full thrust without tripping the limiter of the maximum rotor rpm, under normal ambient conditions on the ground and for various settings for the $\Delta \mathrm{T} 3_{\mathrm{f}}$ parameter

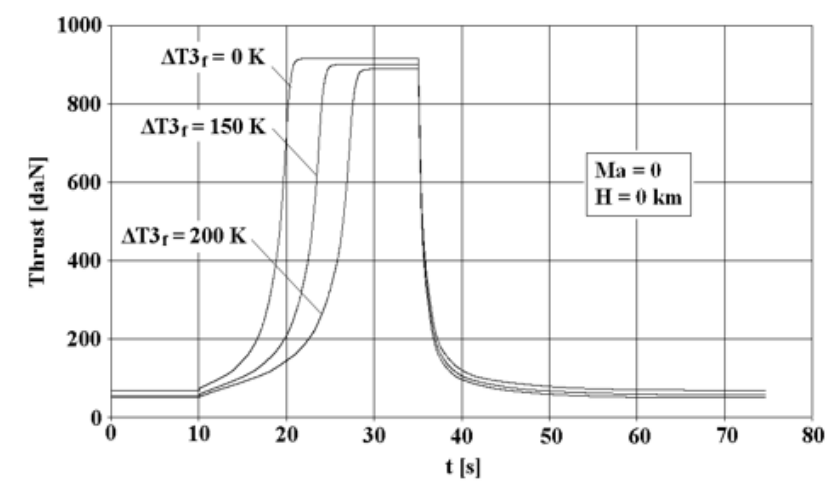

Fig. 11. Timings for the engine thrust during acceleration and deceleration of the jet engine within the range from idle run to the area slightly below full thrust without tripping the limiter of the maximum rotor rpm, under normal ambient conditions on the ground and for various settings for the $\Delta \mathrm{T} 3_{\mathrm{f}}$ parameter

The foregoing results indicate the need to thoroughly examine impact of the $\Delta \mathrm{T} 3_{\mathrm{f}}$ parameter onto static characteristic curves of the engine.

\subsection{Selected static characteristics}

As mentioned before, static characteristic curves for the engine model were determined with use of the own-developed method, called by scanning of the state space. Among other applications the method was also used to find out static characteristic curves of the $\mathrm{K}-15$ engine. The key advantage of the method is the possibility to obtain great many points with measurement results for steady states, where the scanning time is much shorter than it takes place when the conventional method is applied. However, the method has also a drawback, since it can be applied for determination of static characteristic curves merely for single-rotor engines with small volume of the jet nozzle duct, i.e. for such engines where dynamic behaviour thereof can be described by means of the 1st order non-linear differential equation.

The typical property of all other static characteristic curves that are shown in Fig. 12 to Fig. 14 is the fact they substantially differ from each other for various values of the $\Delta \mathrm{T} 3_{\mathrm{f}}$ parameter.

It is worth paying attention that static characteristic curves plotted for the engine for the flight at the altitude of $\mathrm{H}=6 \mathrm{~km}$ feature elevated rotor rpm within the range of idle run, which can be seen from comparison between Fig. 12 and Fig. 13. It is the distinctive property of all avionic turbojet engines and it was correctly reproduced in the simulation model for the SO-3 engine applied to these studies.

\section{CONCLUSIONS}

The investigations enabled to find out substantial impact of temperature field non-homogeneity onto deterioration of both dynamic and static properties of the SO-3 engine. The non-homogeneity leads to a lag of the acceleration time (see Fig. 9 to Fig. 11), which is the crucial parameter for suitability of the engine for use. Also other performance parameters of the engine in its steady state, such as specific fuel consumption per thrust unit and total fuel consumption in time, are considerably higher. It is the phenomenon that can be spotted both for operation of the engine on the ground $(\mathrm{Ma}=0, \mathrm{H}=0)$ and at flight $(\mathrm{Ma}=0.4, \mathrm{H}=6 \mathrm{~km})$.

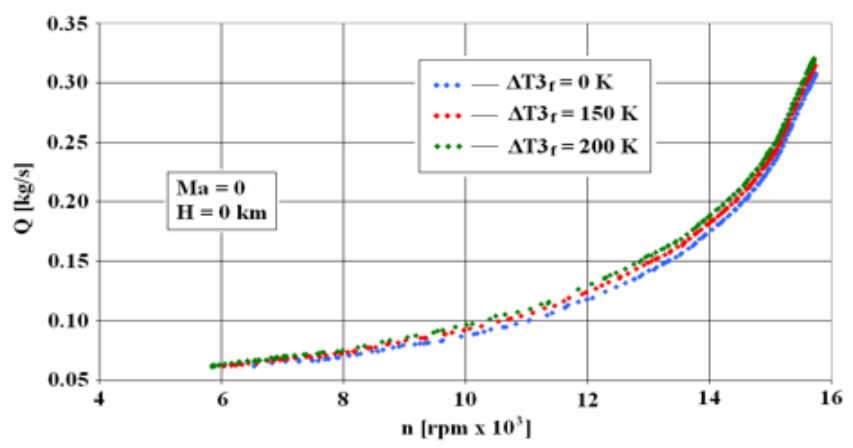

Fig. 12. Static characteristic curves plotted for the jet engine in the coordinate system $\mathrm{Q}=\mathrm{f}(\mathrm{n})$ for various fixed values of the $\Delta \mathrm{T} 3_{\mathrm{f}}$ under normal ambient conditions on the ground

Results from investigations on a real object confirm the impact of the temperature field non-homogeneity within the working agent at the turbine intake onto entire duration of the engine acceleration process underground conditions. The impact of the mentioned temperature field onto specific and total fuel consumption in steady 
states, although revealed by experiments carried out within the scope of these studies, is still awaiting its experimental confirmation.

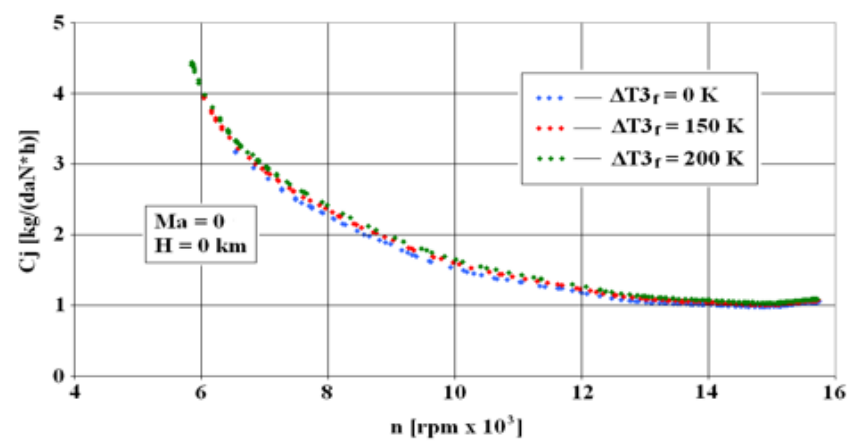

Fig. 13. Static characteristic curves plotted for the jet engine in the coordinate system $C_{j}=f(Q)$ for various fixed values of the $\Delta \mathrm{T} 3_{\mathrm{f}}$ under normal ambient conditions on the ground

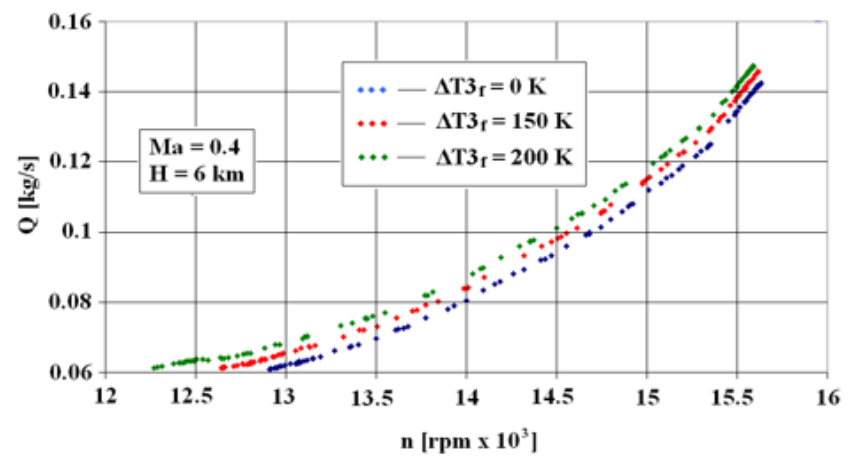

Fig. 14. Static characteristic curves plotted for the jet engine in the coordinate system $\mathrm{Q}=\mathrm{f}(\mathrm{n})$ for various fixed values of the $\Delta \mathrm{T} 3_{\mathrm{f}}$ for the flight at the speed of $\mathrm{Ma}=0.4$ at the altitude of $\mathrm{H}=6 \mathrm{~km}$ under normal ambient conditions

The phenomena described in the Introduction are visible when the conventional parameter that stands for non-homogeneity of the temperature field distribution is large enough, e.g. $\Delta \mathrm{T} 3_{\mathrm{f}}>100 \mathrm{~K}$. Thus, one can expect that for a real engine it will be possible to apply the method disclosed in this paper to define requirements to the permissible maximum of dispersion for the temperature of the working agent.

\section{REFERENCES}

1. Błachnio J., Dięgielewski W., Kułaszka A., Zasada D. (2014), Operation-attributable factors and how they affect condition of heat-resistant coatings of gas-turbine blades, Studies and Proceedings of the Polish Association of Knowledge Management, No. 68, 17-31.

2. Błachnio J., Pawlak W. (2011), Damageability of gas turbine blades - evaluation of exhaust gas temperature in front of the turbine using a non-linear observer, Advances in Gas Turbine Technology, In Tech, 435-464.

3. Bogdan M., Błachnio, J. (2010), A non-destructive method to assess condition of gas turbine blades, based on the analysis of blade-surface image, Russian Journal of Nondestructive Testing, Vol. 46, No. 11, 860-866.

4. Driankov D., Hellendoorn H., Reinfrank M. (1966), Introduction to fuzzy-logic control, WNT, Warsaw.

5. Dzida M. (2000), Identification of reasons for non-stationary and nonhomogenous behaviour of gas temperatures and pressures downstream the combustion chamber of gas turbines, Publishing House of the University of Technology in Gdańsk.

6. Marsh S. (2013), Preventig fretting fatigue in blade dovetail roots by modifying geometry of contact surfaces, Power Transmission Engineering, 28, 45-49.

7. Pawlak W., Wiklik K., Morawski J. M. (1966), Synthesis and investigation of control systems for turbojet engines with use of computer simulation methods, Scientific Library of ITWL, Warsaw.

8. Pawlak W. I. (2000), Influence of an inequality of gas thermal field at the engine turbine inlet on the speed of transient processes - the result of experiments with simulation model, Journal of KONES Internal Combustion Engines, Vol. 7, No. 1-2, 37-42.

9. Pawlak W. I . (2010), Turbojet engine - instruments for simulation, control and monitoring, Scientific Library of the Institute of Aviation, Warsaw.

10. Pawlak W. I., Balicki W. (2003), Influence of an inequality of gas thermal field at the engine turbine inlet on the speed of transient processes - the result of experiments with real engine, Journal of KONES, Vol. 10, No. 3-4, 25-28.

11. Pismenny J., Levy Y. (2002), Local Temperature Regulator In Gas Turbine Engines, International Journal of Turbo\& Jet - Engines, Vol. 10, No. 1-2, 79-92.

12. Spychała J., Pawlak W., Kułaszka A., Błachnio J. (2013), Assessment of technical condition demonstrated by gas turbine blades by processing of images for their surfaces, Journal of KONBIN, 1 (21), 41-50.

13. Stewart I. (2001), Does God play dice. The new mathematics of chaos, PWN Scientific Publications, Warsaw.

14. Swadźba L., Maciejny A., Formanek B., Mendala B. (2008), Characterization of microstructure and properties of TBC systems with gradient of chemical composition and porosity, Archives of Metallurgy and Materials, 53, 945-954.

15. Wróbel Z., Koprowski R. (2004), Practice in image processing within the MATLAB software, EXIT Academic Publishing House, Warsaw.

16. Żóltowski B., Cempel C. (2004), Machinery fault diagnosis engineering, Polish Society of Engineering Diagnosis, Warsaw. 